\title{
Disseminated Pneumocystis carinii infection in AIDS
}

\author{
R J Coker, D Clark, E L Claydon, M Gompels, J G Ainsworth, S B Lucas, R Miller, \\ R D F Goldin, A J Pinching, J R W Harris
}

Department of
Genitourinary
Medicine, St Mary's
Hospital and Medical
School, London
W2 1NF
R J Coker
E L Claydon
J G Ainsworth
J R W Harris
Department of
Histopathology
D Clark
R D F Goldin
Department of
Clinical Immunology
M Gompels
A J Pinching
Department of
Histopathology,
University College and
Middlesex School of
Medicine, London
S B Lucas
Department of
Medicine
R Miller
Correspondence to:
Dr R J Coker
Accepted for publication
9 May 1991

\begin{abstract}
Eight patients with AIDS and Pneumocystis carinii infection were studied. Protean manifestations were a feature not untypical of disseminated pneumocystosis. Aerosolised pentamidine as prophylaxis against $P$ carinii pneumonia was ineffective at suppressing dissemination. The knowledge that extrapulmonary infection can occur has implications for the detection and treatment of, and prophylaxis against, $P$ carinii infection. The survival of patients with disseminated pneumocystosis is particularly poor, and may be due to a lack of clinical awareness and consequent delay in diagnosis.
\end{abstract}

Pneumocystis carinii causes opportunistic infection, most commonly a potentially fatal pneumonia in up to $85 \%$ of patients with AIDS in Europe and North America. ${ }^{1}$ Disease in other organs is reported surprisingly infrequently in view of the multisystem spread of many other organisms in such patients. We describe eight cases of disseminated $P$ carinii infection in patients with AIDS, and highlight the different modes of presentation, the predisposing factors, and the histological features found.

\section{Case reports}

CASE 1

A 36 year old homosexual man presented with a three week history of perianal pain. He had been reported as HIV-1 antibody positive two years previously (July 1987) when he was diagnosed as having $P$ carinii pneumonia. $P$ carinii pneumonia recurred in November 1988 in conjunction with pulmonary tuberculosis. Details of the treatment he received in the USA for these episodes are not available, but he subsequently received aerosolised pentamidine ( $300 \mathrm{mg}$ fortnightly) as secondary prophylaxis. He had had recurrent perianal herpes and developed cryptosporidial diarrhoea in July 1989. Examination showed that he was emaciated, feverish $\left(39^{\circ} \mathrm{C}\right)$, and had oral candidosis and hairy oral leucoplakia. He had a right sided pneumothorax, evidence of cytomegalovirus infection (CMV), retinitis and a $2 \mathrm{~cm}$ ulcerated necrotic perianal mass, which was excised. He developed a left pneumothorax and despite treatment deteriorated and died shortly afterwards.
CASE 2

A 26 year old homosexual man presented with severe abdominal pain. A chest $x$ ray picture on admission showed bilateral pulmonary infiltrates suggestive of $P$ carinii pneumonia. He had been found to be HIV antigen and antibody positive two years previously (November 1988). Mycobacterium malmoense had been isolated from sputum samples in June 1990 and at that time he had started quadruple anti-tuberculous treatment. He had developed an enlarged non-tender thyroid six weeks before admission and was found to be hypothyroid for which he was being treated with thyroxine. Auto-antibodies were not detected. He had received aerosolised pentamidine ( 300 $\mathrm{mg}$ fortnightly) as prophylaxis against $P$ carinii pneumonia for six months. At laparotomy a perforation of the small bowel was found and repaired, but he died seven days later.

\section{CASE $3^{2}$}

A 33 year old homosexual man presented with a history of weight loss, anorexia, dry cough, fever and night sweats. He had been found to be HIV-1 antibody positive three years previously and had developed $P$ carinii pneumonia two years and again 10 months before admission. Since his first episode of $P$ carinii pneumonia he had been maintained on aerosolised pentamidine (300 mg fortnightly). He was feverish $\left(39.4^{\circ} \mathrm{C}\right)$ and cachectic. His chest and abdomen were clinically normal, as were chest $x$ ray picture and arterial blood gas analysis. Bronchoscopy and examination of alveolar lavage specimens yielded normal results. Laboratory data showed raised aspartate transaminase (AST) $(247 \mathrm{IU} / \mathrm{l})$ and alkaline phosphatase (413 IU) activities. Serum bilirubin was normal. The patient subsequently developed liver failure and thrombocytopenia, from which he died one month after admission.

CASE 4

A 26 year old homosexual man was admitted with a history of dyspnoea for one day and fever for five days. He had been diagnosed as HIV-1 antibody positive 18 months earlier when he presented with cutaneous Kaposi's sarcoma. This subsequently became disseminated and was treated with vincristine and bleomycin. He was not taking prophylaxis for $P$ carinii pneumonia. On examination, he was feverish $\left(39.8^{\circ} \mathrm{C}\right)$, tachypnoeic, and had oral hairy leucoplakia and oral candidosis. No abnormalities were detected on examination of the chest. A chest $x$ ray picture showed widespread 
interstitial lung shadowing suggestive of $P$ carinii pneumonia. Arterial blood gas analysis confirmed hypoxia. Liver function tests were only mildly abnormal (AST: $51 \mathrm{IU} / 1$ ). Despite treatment he died two days after admission.

\section{CASE 5}

A 34 year old homosexual man presented with a two week history of fever, malaise, and gradually increasing dyspnoea. He was HIV-1 antibody positive. He had had three previous episodes of $P$ carinii pneumonia over an 18 month period and had developed a rash, when treated with co-trimoxazole during his first attack of pneumonia, and nausea when he was treated with trimethoprim and dapsone during a second. He had responded weli to aerosolised pentamidine during a third episode but had not tolerated pentamidine prophylaxis after this. He had a right tension pneumothorax and a moderate left pleural effusion. Pneumocysts were identified in the pleural aspirate. No other cause for the effusion was identified and he responded to treatment with trimethoprim and dapsone. He died one year later.

\section{CASE 6}

A 44 year old homosexual man presented with a one month history of anorexia, weight loss, and fullness after eating. He had no respiratory symptoms. He had been HIV-1 antibody positive for two years during which time he had received aerosolised pentamidine as primary prophylaxis. He had developed cutaneous Kaposi's sarcoma four months before admission. His liver function tests had been abnor-

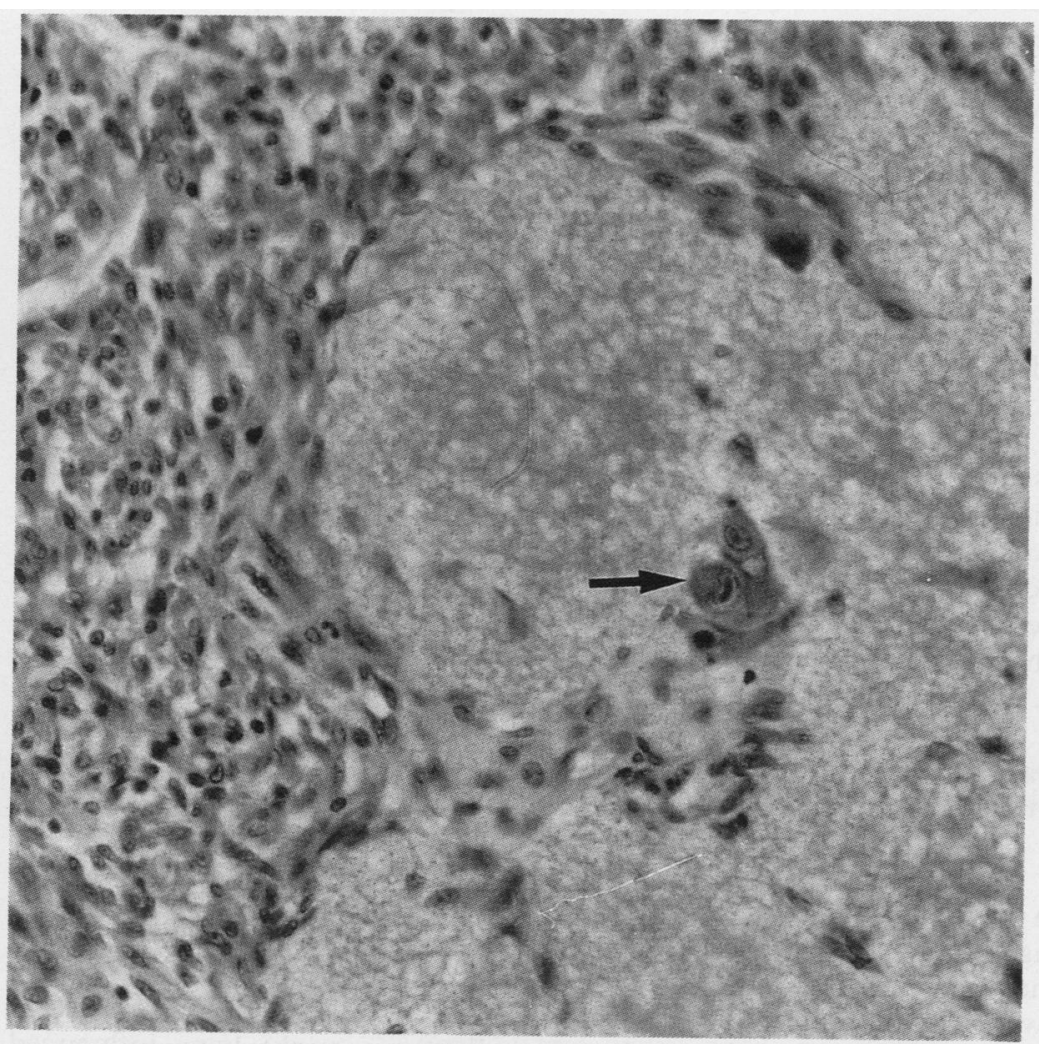

Figure 1 Case 6: small bowel; Kaposi's sarcoma on the left, foamy eosinophilic exudate, characteristic of pneumocystis infection, on the right side of the field. Also note cytomegalovirus infected cells (arrowed) (haematoxylin and eosin). mal for one month (AST $189 \mathrm{IU} / 1$ initially, and $97 \mathrm{IU} / 1$ on admission). His $P$ carinii pneumonia prophylaxis had been changed to dapsone $(100 \mathrm{mg} /$ week) and pyrimethamine (25 mg/week) six weeks before this admission. On examination, he was cachectic, had widespread cutaneous Kaposi's sarcoma, and ascites. A chest $x$ ray picture showed bilateral intersitial shadowing similar to that noted one month earlier. Gastroscopy showed a small pigmented lesion in the stomach. Despite systemic treatment he died six weeks later.

\section{CASE 7}

A 42 year old homosexual man had been found to be HIV-1 antibody positive in August 1987 when he presented with a left lower lobe pneumonia and pleural effusion. He began primary prophylaxis with oral co-trimoxazole but because of intolerance this was changed to aerosolised pentamidine ( $150 \mathrm{mg}$ fortnightly). He had only received one dose of this before he was admitted in December 1988 with $P$ carinii pneumonia. He was treated with aerosolised pentamidine at a dose of $8 \mathrm{mg} / \mathrm{kg}$ for 21 days and made a full recovery. Secondary prophylaxis with aerosolised pentamidine was subsequently given. In May 1990 he presented with B-cell non-Hodgkin's lymphoma affecting the lower lobe of the left lung. He had periventricular changes on a computed tomography scan that were suggestive of intracerebral disease. He developed bilateral interstitial infiltrates thought to be $P$ carinii pneumonia and died despite treatment with intravenous pentamidine ( $4 \mathrm{mg} / \mathrm{kg}$ daily).

\section{CASE 8}

A 31 year old homosexual man was found to be HIV -1 antibody positive in January 1989 . In May 1989 he had an episode of $P$ carinii pneumonia which was treated successfully with aerosolised pentamidine ( $8 \mathrm{mg} / \mathrm{kg}$ for 21 days), and he subsequently began secondary $P$ carinii pneumonia prophylaxis with aerosolised pentamidine (150 mg fortnightly). In January 1990 he developed a left pneumothorax which resolved spontaneously. He developed a further pneumothorax, on the right, later the same month which required a chest drain. On reinflation of the lung, a chest $x$ ray picture showed bilateral perihilar shadowing, suggestive of $P$ carinii pneumonia. He developed a left pneumothorax two days later that required an intercostal drain. Despite treatment with intravenous high dose co-trimoxazole he continued to have bilateral air leaks, complicating bilateral pneumonia and he died.

\section{Biopsy findings}

An antemortem diagnosis of extrapulmonary pneumocystosis was made on biopsy specimens of perianal skin, small bowel, and gastric body in cases 1,2 , and 6 , respectively. In cases 3 and 4 the diagnosis was made on a postmortem needle necropsy specimen of the liver. In cases $1,2,3$, and 6 the histological diagnosis was initially suspected because of the presence of frothy pink exudate similar to that seen in 


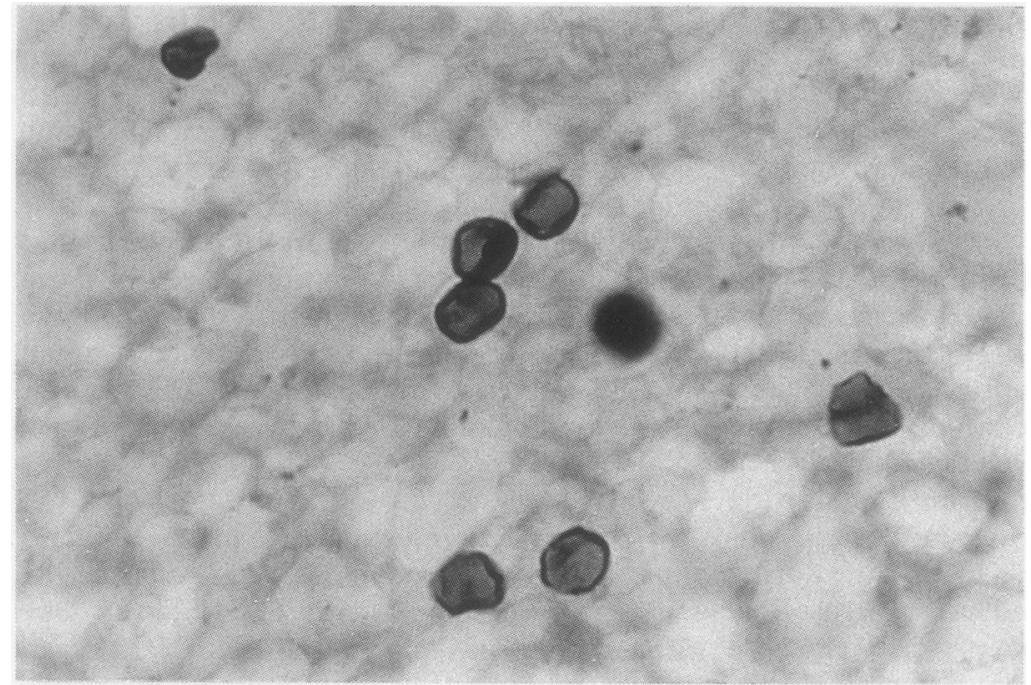

Figure 2 Case 6: cyst forms of Pneumocystis carinii (Grocott's methenamine silver stain). calcification within the pneumocystosis. CMV infection was widespread in the lungs, gut, spleen, nodes and adrenal glands.

CASE 8

Both lungs showed yellow cavitating consolidation (left weighing $800 \mathrm{~g}$, right weighing $1050 \mathrm{~g}$ ), and the hilar nodes showed yellow infiltration. The remaining organs were macroscopically normal. Histologically, the lung and nodes showed calcifying $P$ carinii infection. $P$ carinii and a focal granulomatous reaction had infiltrated and occluded the arteries of the lungs. CMV infection was present only in the adrenal glands.

\section{Discussion}

Dissemination of $P$ carinii infection is rare, but is increasingly being reported in patients with AIDS. This series includes: the first patients to be reported with perianal infection; the first patient to develop hypothyroidism secondary to $P$ carinii thyroiditis; the first patient to develop bowel perforation; and the first reported cytological documentation of $P$ carinii in pleural fluid in the absence of concurrent ipsilateral pneumothorax.

Of the 585 episodes of $P$ carinii infection (397 patients) treated at St Mary's and the Middlesex Hospitals up to November 1990, only these eight $(0.5 \%)$ patients had evidence of extrapulmonary spread. The incidence of disseminated $P$ carinii infection documented here is lower than that reported previously, but the incidence of clinical disease is similar. In a review of 161 necropsies of patients with AIDS, 55 had $P$ carinii pneumonia; four $(2.5 \%)$ had extrapulmonary $P$ carinii infection, but only one had clinical evidence of this. ${ }^{3}$ Extrapulmonary sites in which $P$ carinii infection has been documented include the spleen, ${ }^{4}$ liver, ${ }^{3-5}$ kidney, ${ }^{34}$ bone marrow, ${ }^{3}$ auditory canal, ${ }^{6}$ thyroid, ${ }^{47}$ lymph nodes, ${ }^{45}$ gastrointestinal tract, ${ }^{48}$ eye $^{9}$ and brain. ${ }^{10}$

Disseminated $P$ carinii infection was first reported in $1960 .{ }^{11}$ LeGolvan and Heidelberger reviewed seven cases in 1973 but could not identify any predisposing underlying factors to determine which patients would develop disseminated disease. ${ }^{12}$ Lymphatic and haematogenous spread occurs, but risk factors predisposing to dissemination have still not been elucidated. As in most previously reported studies, ${ }^{3-10}$ most of the patients reported here had had either a previous episode of $P$ carinii pneumonia or had $P$ carinii pneumonia at the time of presentation with extrapulmonary disease. This may have been due to more aggressive disease being present, and lung destruction might have been more extensive, because of variations in the invasiveness of the organisms, or unknown systemic factors. The mortality from disseminated disease is high, as shown by the poor survivals seen in these and previous cases. The pneumocystosis in cases 1 , $2,3,4$, and 6 probably contributed to death, and earlier diagnosis might have influenced outcome.

The true incidence of disseminated disease is widespread $P$ carinii pneumonia with tion, and the $P$ carinii was intermingled with the lymphoma. The sinuses of the hilar lymph nodes were infiltrated by $P$ carinii, but not by lymphoma. Histologically, there was much 
probably underestimated for various reasons. The disease may respond to systemic treatment; post mortem examinations are not always performed; the organism is often not specifically sought in extrapulmonary sites.

Perianal disease as a result of $P$ carinii infection has not previously been reported, although associated disease of the oesophagus, duodenum, appendix, jejunum and thyroid have. ${ }^{48}$ The hypothyroidism noted in case 2 several weeks before his final admission was probably caused by infection in this organ. This patient also had a perforation of his small bowel. This has not previously been associated with pneumocystosis, but, histologically, the extensive pneumocystis infection seemed to be the cause of the perforation, although the coexistent $\mathrm{CMV}$ infection may also have played a part. ${ }^{1314}$ There are no reports of Kaposi's sarcoma with perforation in cases of AIDS without CMV infection, ${ }^{2}$ implying that Kaposi's sarcoma is not destructive enough to cause perforation of the gastrointestinal tract.

Colonisation of the liver by $P$ carinii (cases 2 , 3 , and 4) is commonly seen when dissemination occurs. Six of the 10 cases reviewed by Northfelt ${ }^{15}$ had some hepatic disease although none developed hepatic failure. Jenkins et $a l^{16}$ reporting on case 3, have discussed the occurrence of unrecognised $P$ carinii hepatitis and resultant hepatic failure.

In case 5 pneumocysts were isolated from the pleural effusion on the contralateral side to the pneumothorax. Though pleural effusions in $P$ carinii pneumonia ${ }^{17}$ and isolation of $P$ carinii from the pleura have been reported, ${ }^{18}$ we are unaware of pneumocysts being isolated from this site unless there is concurrent ipsilateral pneumothorax. ${ }^{19}$

There has recently been concern over the use of pentamidine possibly being responsible for the increased incidence of pneumothoraces. ${ }^{20}$ This was noted in cases 1,5 , and 8 , all of whom were receiving aerosolised pentamidine.

Six of the eight patients presented here had received aerosolised pentamidine (through Respigard II nebulisers) as either primary (cases 2 and 6) or secondary (cases 1, 3, 7, and 8) prophylaxis for $P$ carinii pneumonia. The usual portal of entry of $P$ carinii is the lung, and aerosolised pentamidine is attractive because high concentrations can be attained in the lungs, it is well tolerated, and has not resulted in clinically important toxicity. It may be, however, that aerosolised pentamidine is an effective prophylactic agent against pneumonia but ineffective in preventing dissemination of the infection. Moreover, the absence of pneumonia may cause the diagnosis of extrapulmonary pneumocystosis to be overlooked. Dissemination could occur during the initial infection but the occurrence in two cases receiving primary prophylaxis means that the extrapulmonary spread does not only occur during the first clinical episode of $P$ carinii pneumonia in AIDS, and that the use of aerosolised pentamidine, though an effective agent for prophylaxis for pneumonia, is ineffective at suppressing extrapulmonary pneumocystosis. ${ }^{1621}$ This may be relevant when choosing prophylaxis in the future.

In summary, the cases reported here show the protean manifestations of disseminated pneumocystosis. Physicians must be aware of the unusual sites of infection, especially in patients not receiving any prophylaxis or receiving prophylaxis in the form of aerosolised pentamidine. Pathologists should be alerted to look specifically for pneumocysts in biopsy samples from HIV antibody positive patients whatever the tissue, because earlier diagnosis and systemic treatment may improve survival.

1 Murray JF, Garay SM, Hopewell PC, Mills J, Snider GL Stover DE. Pulmonary complications of the acquired immune deficiency syndrome. An update. Am Rev Respir Dis 1987;135:504-9.

2 Friedman SL, Wright TL, Altman DF. Gastrointestinal Kaposi's sarcoma in patients with acquired immunodeficiency syndrome: endoscopic and autopsy findings. Gastroenterology 1985;89:102-8.

3 Telzak EE, Cote RJ, Gold JWM, Campbell SW, Armstrong D. Extrapulmonary Pneumocystis carinii infections. Rev Infect Dis 1990;12:380-6.

4 Macher AM, Bardenstein DS, Zimmerman LE, Steigman CK, Pastore L, Poretz DM, Eron LJ. Pneumocystis carinii choroiditis in a male homosexual with AIDS and disseminated pulmonary and extrapulmonary $\mathbf{P}$ carini infection. N Engl J Med 1987;316:1092.

5 Afessa B, Green WR, Williams WA, Hagler NG, Gumbs RV, Hackney RL, Frederick WR. Pneumocystis carini pneumonia complicated by lymphadenopathy and pneumothorax. Arch Intern Med 1988;148:2651-4.

6 Breda SD, Gigliotti F, Hammerschlag PE, Schinella R Pneumocystis carinii in the temporal bone as a primary manifestation of the acquired immunodeficiency syndrome. Ann Otol Rhinol Laryngol 1988;97:427-31.

7 Gallant JE, Enriquez RE, Cohen KL, Hammers LW. Pneumocystis carinii thyroiditis. Am J Med 1988;84: 303-6.

8 Grimes MM, LaPook JD, Bar MH, Waserman HS, Dwork A. Disseminated Pneumocystis carinii infection in a patient with acquired immunodeficiency syndrome. Hum Pathol 1987;18:307-8.

9 Sneed SR, Blodi CF, Berger BB, Speights JW, Folx JC, Weingeist TA. Pneumocystis carinii choroiditis in patients receiving inhaled pentamidine. $N$ Engl J Med 1990;322:936-7.

10 Mayayo E, Vidal F, Alvira R, Gonzalez J, Richart C. Cerebral Pneumocystis carinii infection in AIDS. Lancet 1990;336:1592.

11 Anderson CD, Barrie HJ. Fatal Pneumocystis pneumonia in an adult. Am J Clin Pathol 1960;34:365-70.

12 LeGolvan, Heidelberger KP. Disseminated, granulomatous Pneumocystis carinii pneumonia. Arch Pathol 1973; 95:344-8.

13 Jacobson MA, Mills J. Serious cytomegalovirus disease in the acquired immunodeficiency syndrome (AIDS). Ann Intern Med 1988;108:585-94.

14 Frank D, Ratent RF. Intestinal perforation associated with cytomegalovirus infection in patients with acquired immunodeficiency syndrome. Am J Gastroenterol 1984; 79:201-5.

15 Northfelt DW. Extrapulmonary pneumocystosis in patients taking aerosolised pentamidine. Lancet 1989;ii:1454.

16 Jenkins RE, Goldin RD, Lindley RP, Pinching AJ. Aerosolised pentamidine. Lancet 1990;i:113.

17 Naidich DP, Garay SM, Lutman BS, McCauley DI. Radiographic manifestations of pulmonary disease in the acquired immunodeficiency syndrome (AIDS). Semin Roentgenol 1987;22:14-30.

18 Dyner TS, Lang W, Busch DF, Gordon PR. Intravascular and pleural involvement by Pneumocystis carinii in a patient with the acquired immunodeficiency syndrome (AIDS). Ann Intern Med 1989;111:94-5.

19 Balachandran I, Jones DB, Humphrey DM. A case of Pneumocystis carinii in pleural fluid with cytologic, histologic and ultrastructural documentation. Acta Cytol tologic and ultrast

20 Martinez CM, Romanelli A, Mullen MP, Lee M. Spontaneous pneumothoraces in AIDS patients receiving aerosoleous pneumothoraces in AIDS patients
ised pentamidine. Chest 1988;94:1317. 21 Armstrong D, Bernard E. Aerosol pentamidine. Ann Intern
Med 1988;109:852-4. 